\title{
BRYOZOAN REBOUND(?) FROM PERMIAN EXTINCTIONS
}

HOROWITZ, Alan S., Department of Geological Sciences, Indiana University, 1005 East 10th Street, Bloomington, IN 47405, U.S.A.; PACHUT*, Joseph F., Department of Geology, Indiana University-Purdue University at Indianapolis, 723 West Michigan Street, Indianapolis, IN 46202, U.S.A.

Permian bryozoans declined in the latest Permian, probably as a consequence of the reduction in continental seas. Depending on the rank given some major Permian bryozoan groups, 1 order (Cryptostomatida) or 3 orders (Rhabdomesida, Fenestrida, Cryptostomatida) became extinct at the end of the Permian. Although 4 orders survived, they were much reduced in taxonomic diversity and abundance. Two of the 4 orders that survived the Permian were extinct by the end of the Triassic. Consequently, they secondarily rebounded from the Triassic extinction and did not achieve a rock-forming significance comparable to their Paleozoic forebears until the end of the Cretaceous. Today they are dominant sediment contributors in very few areas.

A new order, the Cheilostomatida arose in the late Jurassic. Interestingly, the boxlike zooecial constructions of the cheilostomes is a feature utilized by the most successful late Paleozoic bryozoans, the fenestrates, and cheilostomes increased in diversity and abundance through the Cretaceous until they became the dominant bryozoan group. The post-Paleozoic rebound was very gradual and required most of the Mesozoic to achieve Paleozoic diversity and rock-forming contributions. Diversity peaks in the Carnian (Triassic) and middle Jurassic were apparently related to an increase in the area of continental seas. 